ISSN 2236-0859

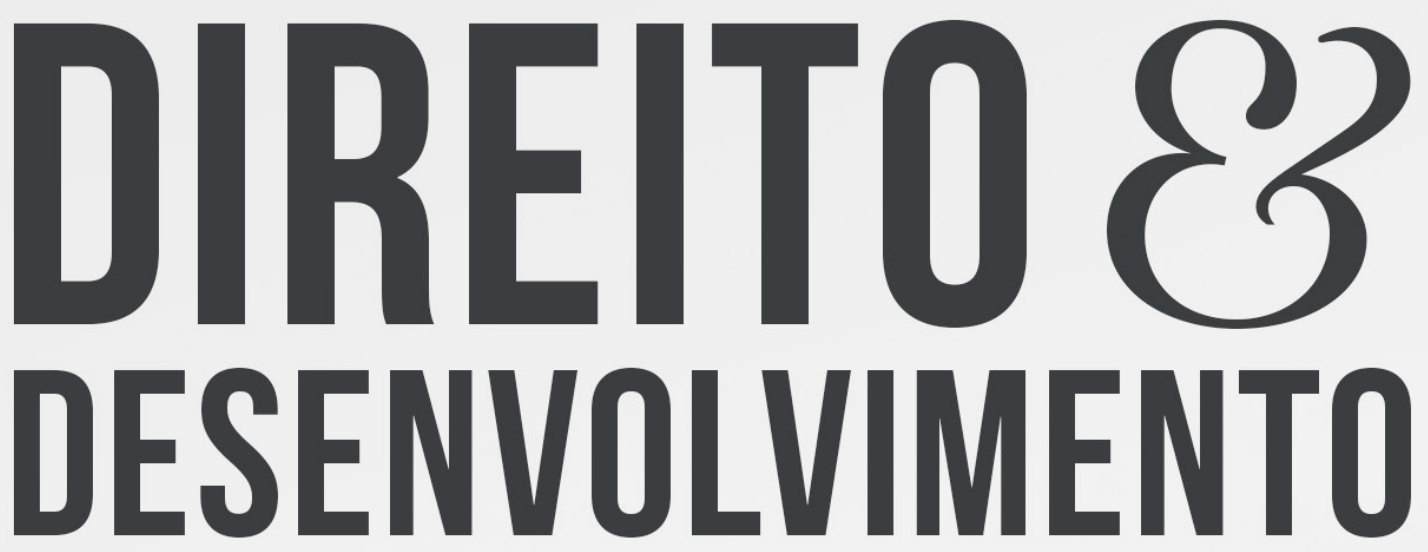

REVISTA DO PROGRAMA DE PÓS-GRADUAÇÃO EM DIREITO MESTRADO EM DIREITO E DESENVOLVIMENTO SUSTENTÁVEL

O INVESTIMENTO-ANJO COMO INSTRUMENTODE DESENVOLVIMENTO ECONÔMICO NO BRASIL

KHAREN KELM HERBST

EDUARDO OLIVEIRA AGUSTINHO 


\section{O INVESTIMENTO-ANJO COMO INSTRUMENTO DE DESENVOLVIMENTO ECONÔMICO NO BRASIL}

\section{THE ANGEL INVESTMENT AS AN INSTRUMENT OF ECONOMIC DEVELOPMENT IN BRAZIL}

Recebido: 24/10/2019

Aprovado: 21/11/2019
Kharen Kelm Herbst ${ }^{1}$

Eduardo Oliveira Agustinho ${ }^{2 \dagger}$

\section{RESUMO:}

Diante dos arranjos institucionais brasileiros, dependentes de sua trajetória, o empreendedorismo se depara com diversos obstáculos que representam riscos e desestímulos à inovação, entre eles a dificuldade para acessar recursos financeiros bancários. Neste cenário, o investimentoanjo despontou como uma alternativa promissora. Observada a sua progressiva relevância no mercado, cabe ao Estado proporcionar as instituições jurídicas que garantam maior segurança para a transação. O objetivo deste artigo, então, é analisar de que forma as instituições foram formalizadas para mitigar os riscos dessas operações de investimento, e se asseguram a eficiência de potencializar esse mecanismo de desenvolvimento econômico no Brasil. Através da técnica bibliográfica e método dedutivo, foram aplicados os fundamentos da Nova Economia Institucional, desvendando os resultados esperados da interseção entre instituições jurídicas e econômicas no contexto do investimento-anjo.

Palavras-chave: Desenvolvimento. Nova economia institucional. Investimento-anjo. Dependência de trajetória. Empreendedorismo.

\section{JEL: K20. Koo}

\section{ABSTRACT:}

Considering the institutional arrangements existing in Brazil as a result of the path dependence, entrepreneurship faces many obstacles discouraging innovation, including the difficulty of raising financial resources through banks. In this scenario, angelinvestment has emerged as a promising alternative. Due to its progressive relevance in the market, the state must provide proper legal institutions to ensure legal certainty for these transactions. The purpose of this paper, therefore, is to analyze how the legal institutions and regulation are being formalized to mitigate risk on these investment operations, and ensure the efficiency of potentializing this mechanism of economic development in Brazil. Through the bibliographical technique and deductive method, the foundations of the New Institutional Economics are applied, unveiling the results of the interaction between legal and economic institutions in the context of the angel investment.

1 Mestranda em Direito Econômico e Desenvolvimento - PPGD da PUCPR. Advogada . Email: kharen_k@hotmail.com 2 Doutorado em Direito Econômico e Socioambiental na Pontifícia Universidade Católica do Paraná - PUCPR. Mestre em Integração Latino-Americana pela Universidade Federal de Santa Maria. Professor Titular de Direito Empresarial no Curso de Graduação em Direito da PUCPR e Decano da Escola de Direito da PUCPR. Professor Convidado da FAE. Leciona em Cursos de Pós-Graduação lato sensu da PUCPR, Esmafe e ABDCONST. Email: eduardo.agustinho@pucpr.br 
Keywords: Development. New institutional economics. Angel investment. Path dependence. Entrepreneurship.

\section{INTRODUÇÃO}

O desenvolvimento econômico depende diretamente da dinâmica empresarial do país, que aumenta a geração de empregos, a criação de inovações, a produtividade e circulação de recursos como um todo. A dinâmica empresarial, por sua vez, depende dos arranjos institucionais vigentes, da interação entre instituições jurídicas e instituições econômicas.

Ocorre que os arranjos institucionais são determinados pela trajetória histórica, social e cultural, que torna enraizados alguns aspectos da conduta dos agentes e o modus operandi da economia, especialmente no âmbito regulatório e nas formas de intervenção estatal através de políticas públicas variadas.

No Brasil, a presença do Estado na economia sempre foi pujante, onde assume os papeis de empresário, fomentador, regulador e fiscalizador. No sistema financeiro não é diferente. Os bancos públicos financiam grande parte dos investimentos de risco e de longo prazo de maturação. Entretanto, não têm sido suficientes para propiciar um ambiente de inovações, que aceleraria o desenvolvimento econômico nacional.

Diante da insuficiência do Estado de prover estes recursos, o setor privado vislumbrou oportunidades de importar para o Brasil a modalidade de investimento-anjo. O investimentoanjo é uma alternativa que traz grandes benefícios para ambas as partes - o investidor e a empresa investida - pois se trata de smart money, que combina os recursos financeiros com o know-how e mentoria do empresário mais experiente para o principiante. Esta transação reduz os riscos de insucesso para a empresa, diante da possibilidade de contar com orientações e rede de contatos de empresários tarimbados. Por outro lado, o investidor pode ampliar sua carteira de negócios sem correr riscos societários, tributários e trabalhistas enquanto a empresa ainda está em fase experimental. A estrutura societária e de capital da empresa é reajustada conforme o negócio evolui.

Dessa forma, o investimento-anjo torna-se um meio para contornar a trajetória brasileira de dependência do setor público para inovações e financiamentos corporativos, fortalecendo a parceria entre agentes privados.

Nesta conjuntura, é imprescindível que as instituições jurídicas acompanhem o movimento da economia, mitigando os pontos que podem gerar uma insegurança na transação, para, então, permitir que o investimento-anjo atinja o potencial máximo no Brasil, como um verdadeiro fomentador do desenvolvimento econõmico, ampliando capacidades e oportunidades do empreendedorismo e inovações no país.

Diante disso, o presente artigo inicia com uma análise acerca de como os arranjos institucionais interferem diretamente no desenvolvimento econômico, ao definir as bases do ambiente negocial. Passa-se, em seguida, para uma observação do atual cenário brasileiro, como decorrente da trajetória institucional. Dentre as diversas instituições jurídicas e econômicas, identifica-se, então, quais se aplicam ao contexto do investimento-anjo e são primordiais para a eficiência dessas transações, que se apresentam como um efetivo instrumento de viabilização do desenvolvimento econômico.

Realizou-se pesquisa teórica, através da técnica bibliográfica e do método dedutivo, utilizando fundamentos da Nova Economia Institucional, compreendendo os custos de transação e problemas de agência envolvidos no investimento-anjo, para concluir que instituições jurídicas eficientes oportunizam resultados positivos quando são capazes de 
aumentar os níveis de confiança mútua nas transações econômicas, sem retirar o espaço de flexibilidade negocial que uma sociedade em constante evolução impõe.

\section{INSTITUIÇÕES PARA O DESENVOLVIMENTO ECONÔMICO}

Os estudos sobre o desenvolvimento econômico tornam-se cada vez mais relevantes e aprofundados na esfera jurídica diante das concepções de que não se restringe apenas ao aumento da riqueza, mas abrange também questões sociais e de qualidade de vida para a população, e de que o Estado não é necessariamente um obstáculo ao mercado, é sobretudo uma das entidades que o viabilizam (REIS, 2011, p.20).

Segundo Moreira (1978, p.11-12), o capitalismo não é apenas um fato econômico, é também um fato jurídico e político, e um sistema social. No modus vivendi do capitalismo contemporâneo, o Estado é responsável pelo curso da economia, através de políticas e regulações. Estado e mercado, portanto, funcionam em profunda simbiose.

Sendo assim, a forma como o Estado intervém - ou se abstém de intervir - nas relações entre os agentes econômicos, pode acelerar ou frear o desenvolvimento da nação.

\footnotetext{
O desenvolvimento econômico supõe uma sociedade capitalista organizada na forma de um estado-nação onde há empresários e trabalhadores, lucros e salários, acumulação de capital e progresso técnico, um mercado coordenando o sistema econômico e um estado regulando esse mercado e complementando sua ação coordenadora. (BRESSERPEREIRA, 2007, p.1)
}

Essa dinâmica ocorre a partir das instituições que delimitam e organizam o papel dos agentes públicos e privados nas sociedades. As instituições, conforme a linha teórica da Nova Economia Institucional, são as regras do jogo, ou, as estruturas que coordenam as interações e a alocação de recursos, funcionando "como um tipo de contexto de racionalidade, que emerge das interações humanas e simultaneamente as governa. [...] as instituições não apenas definem e delimitam o conjunto de ações disponíveis para os indivíduos; elas simultaneamente são moldadas pelos indivíduos e tornam suas interações possíveis" (SJOSTRAND, 1995, p.19).

Para Marcia Carla Pereira Ribeiro e Irineu Galeski Junior, as instituições estabelecem "um complexo de ações possíveis, que devem ser consideradas como parte de um sistema, e que compõem o sistema formal de instituições, quando incorporadas pelo direito, e o informal, na hipótese de não incorporação" (RIBEIRO e GALESKI, 2009, p. 186).

Inicialmente, as instituições formais basilares do capitalismo consistiam na propriedade privada e no contrato (MOREIRA, 1978, p.12). Atualmente, existe um universo de muitas e diversas regras às quais se submetem os agentes econômicos, como a legislação trabalhista, societária, tributária, concorrencial, as regras que regem o mercado financeiro, e outras.

Para Ronald Coase, a eficiência do mercado e, portanto, seu pleno desenvolvimento, depende das instituições de um país - o sistema legal, o sistema político, o sistema de educação, a cultura. Estas instituições governam o desempenho do sistema econômico (COASE, 1999, p. 04).

Da eficiência das instituições depende a produtividade, que varia de acordo com as diferenças tecnológicas, os processos e o ambiente em que a produção de bens ou serviços ocorre, abrangendo o conhecimento adequado dos recursos limitados e seus métodos de utilização para gerar a maior quantidade de bens e serviços, com qualidade proporcional, em um determinado período de tempo; o nível de investimentos nacionais e estrangeiros, que variam de acordo com os incentivos e condições presentes nas empresas e no país onde 
se pretende investir; entre outros fatores determinantes para o desenvolvimento econômico nacional ou mesmo de um setor específico do mercado.

Os caminhos para o desenvolvimento, portanto, implicam a escolha das instituições mais apropriadas, que decorrem, "num primeiro momento, das combinações acertadas de Estado e de mercado" (REIS, 2011, p.19).

Isso ocorre porque, ao contrário do que preconiza o pensamento econômico liberal (BUTLER, 2015, p.74), a realização de negócios exclusivamente por meio do mercado, sem intervenção estatal, não conduz invariavelmente aos melhores resultados, havendo situações em que há custos de transação - estes, compostos pelos custos de procura, de negociação, de decisão, de monitoramento e de sanção - que podem ser mitigados por uma regulação adequada, que também pode prevenir os comportamentos oportunistas e consequências de racionalidade limitada por parte dos agentes envolvidos (COASE, 1960, p.15).

Ou seja, "os custos de transação referem-se não ao custo das mercadorias, bens e serviços em si mesmos ou aos custos de produção, mas aos custos, como o próprio nome indica, da transação" (GONÇALVES e RIBEIRO, 2015, p. 464). Por isso, normas e instituições jurídicas impactam fortemente na esfera econômica e empresarial quando, através de mecanismos de controle legais ou contratuais, aumentam ou reduzem a complexidade do ambiente negocial e alteram as perspectivas das tomadas de decisões dos agentes envolvidos (GONÇALVES e RIBEIRO, 2015).

Na ausência de instituições eficientes, dada a incerteza, os custos de transação tornamse muito altos e os negócios podem não se consumar, inviabilizando que o mercado atinja o seu potencial máximo (SCHAPIRO, 2010, p.217).

Os ensinamentos de Douglass North (1990 e 1994), igualmente, colocam o Estado nesta posição central, esclarecendo que as soluções econômicas repousam menos nos avanços tecnológicos e na acumulação de capital do que nos arranjos institucionais que estimulam ou inibem as atividades neste sentido. Ou seja, "o que a literatura econômica considera causas do crescimento nada mais são do que consequências de uma dada matriz institucional específica" (GALA, 2003, p.93).

North, então, abarca os preceitos de Coase, ao resumir que "when it is costly to transact, institutions matter" (NORTH, 1990, p.12).

Conforme a sociedade evolui, as instituições se reinventam com a finalidade de atender às necessidades do convívio social. Especialmente no que tange à esfera econômica, não são raras as vezes em que a ordem dos acontecimentos é, primeiramente, de surgimento de instituições informais, que posteriormente são formalizadas pelo Direito, como é o caso de novos modelos de negócios e novos formatos de relações comerciais que emergem, e que, em seguida, passam a ser regulados para proporcionar segurança jurídica.

Atualmente, há maior desenvolvimento econômico nos países onde há maiores possibilidades de inovar de forma bem-sucedida. Neste ponto, instituições jurídicas podem interferir estimulando o potencial desenvolvimento, criando leis que aprimoram o funcionamento das empresas e dos mercados, que são as instituições econômicas (COOTER e SCHAFER, 2013, p.22).

Enquanto já não mais se discute acerca da possibilidade das instituições jurídicas produzirem bons resultados econômicos, prevalece o debate acerca de quais seriam as regras jurídicas ideais, levando em conta o seu impacto nas empresas, em setores específicos do mercado e, ainda, na sociedade como um todo. Sendo certo que não há garantias de que as instituições que tiveram bons resultados em um país desenvolvido, necessariamente surtirão os mesmos efeitos em um país em desenvolvimento, sendo imprescindível analisar fatores históricos, culturais e políticos que estão firmados onde serão aplicadas as regras jurídicas. As 
instituições e, sobretudo, as mudanças institucionais são dependentes da trajetória nacional (TREBICOOK e DAVIS, 2009).

\section{A DEPENDÊNCIA DE TRAJETÓRIA BRASILEIRA NAS FORMAS DE FINANCIAMENTO CORPORATIVO}

Cada país é um sistema singular, com características que foram moldadas pelo seu processo de formação histórica, de forma que as soluções também devem ser singulares, assimilando a realidade existente (RISTER, 2007, p.14). A regulação econômica para o desenvolvimento, portanto, varia de acordo com os sistemas de valores, as condições e as estruturas vigentes em uma determinada sociedade e em um determinado momento, e deverá, por essa mesma razão, ser constantemente reformulada e adaptada de acordo com as mudanças que ocorrem nessa sociedade.

As instituições, portanto, não são transplantáveis de um país para outro, de viés one size fits all. Deve haver uma consistência com a trajetória histórica vivenciada pelos arranjos nacionais (SCHAPIRO, 2010). North (1990) esclarece que, para além da noção de que institutions matter, não se pode olvidar que history matters.

A evolução do capitalismo nos diversos países não se deu de forma igual. Há países dominantes e países dominados (MOREIRA, 1978). Para Nasser (2005), uma regulação eficiente é o produto final obtido em uma equação que envolve muito mais do que apenas normas, convenções, costumes e regras. Trata-se de uma estratégia estatal que tenta conciliar necessidades e interesses, a partir de sua posição na ordem mundial.

A evolução um pouco mais tardia do capitalismo no Brasil determinou a sua condição de país semiperiférico da economia mundial (ALCOFORADO, 2006), que somente pode ser superada através de instituições e políticas públicas acertadas, sobretudo aquelas que incentivam empreendedorismo, confiança no ambiente negocial e inovação - sendo esta entendida por Cooter e Schafer (2013), como o principal catalisador do crescimento econômico.

No caso dos países em desenvolvimento, houve uma tendência a privilegiar a industrialização através de investimentos realizados ou regulados pelo Estado, notadamente através de empresas estatais e de programas de investimento no setor público (FIANI, 2001).

Durante o período de industrialização brasileiro, havia poucos mecanismos de investimentos privados e pouco capital acumulado, sendo necessário voltar-se para o apoio de instituições internacionais, captando empréstimos através das empresas estatais que, pelo orçamento público, obtinham melhores condições de crédito do que as empresas privadas (ALMEIDA, 2003).

Desde então, financiamentos de atividades de maior risco têm contado com os bancos públicos, como o Banco Nacional de Desenvolvimento Econômico e Social - BNDES e o Banco do Brasil, que se estabeleceram como os dominantes financiadores do desenvolvimento econômico (SCHAPIRO, 2010).

A opção por bancos públicos, entretanto, é uma espécie de second best institucional, isto é, uma solução alternativa introduzida por governos que são incapazes de estabelecer um ambiente institucional adequado, e, diante das fragilidades da organização jurídica, o Estado compensaria as incertezas dos investidores privados, retraídos em razão da debilidade do ambiente institucional. Os bancos públicos, até os dias atuais, permanecem desempenhando um papel-chave na economia brasileira, sendo responsáveis pela maior parte dos financiamentos corporativos (SCHAPIRO, 2010). 
Estas escolhas que foram realizadas no momento de formação das instituições capitalistas brasileiras e suas políticas, ainda exercem um efeito de constrangimento sobre o desenvolvimento presente e futuro, em razão da tendência inercial das instituições que dificulta subsequentes mudanças, mesmo diante de ineficiências (BERNARDI, 2012). A dependência de trajetória não é absoluta ou permanente (TREBICOOK e DAVIS, 2009), mas as mudanças exigem grande esforço:

A dependência da trajetória é conceitualizada [...] como processos dinâmicos contingentes não-reversíveis, cujo conteúdo central se refere à ideia da história como um processo de ramificação (branching) irreversível, no qual os custos de transição para uma alternativa previamente descartada se acumulam com o tempo, tornando tal mudança cada vez menos provável por mais que a alternativa escolhida mostre-se menos eficiente que algumas das opções antes (ou ainda) disponíveis. (BERNARDI, 2012, p.142)

Existe um autorreforço institucional, onde a reprodução de uma instituição acontece porque os agentes consideram-na legítima e, assim, optam voluntariamente por sua continuidade, ou seja, a instituição existente é favorecida porque é vista como legítima, mas o seu favorecimento é que reforça sua legitimidade (BERNARDI, 2012).

Embora as opções de financiamentos tenham sido diversificadas no país - contando com o aprimoramento do mercado de capitais, venture capital e investimentos-anjo -, o cenário econômico brasileiro requer, ainda, uma mudança cultural, que depende do fortalecimento da confiabilidade no entorno institucional de promoção e segurança jurídica das transações e investimentos de risco entre agentes privados, para atender as expectativas de crescimento e modernização econômica.

Na década de 1990, reformas jurídico-institucionais foram promovidas com o objetivo de privatizar bancos e impulsionar o ambiente financeiro nacional, expandindo a concorrência, inclusive permitindo a entrada de players estrangeiros, na intenção de reduzir custos de captação de recursos e diversificar fontes privadas de financiamento corporativo, ampliando a proteção jurídica a investidores e credores, aprimorando mecanismos de governança (SCHAPIRO, 2010):

\footnotetext{
A premissa de análise é a de que em um ambiente inseguro, dotado de uma proteção deficiente dos direitos de investidores, ou notabilizado por regras imprecisas e sujeitas a ampla margem de controvérsias, os investidores tendem a restringir a sua disposição em prover recursos monetários, o que, enfim, pode comprometer o volume de capital disponível para as atividades de financiamento corporativo. (SCHAPIRO, 2010, p.224)
}

Essas reformas jurídicas consistem em tentativas de mitigar custos de transação que podem desencorajar os investimentos. Mas, apesar dos esforços, estas reformas tiveram como ponto central o financiamento corporativo através do mercado de capitais, privilegiando alterações na Lei das Sociedades Anônimas (através da Lei 10.303 / 2001) e a criação de novos mercados autorregulados na Bovespa, com regras rígidas de governança corporativa (Novo Mercado, Nível 1 e 2 e Bovespa Mais).

Neste ponto, algumas peculiaridades do setor empresarial brasileiro precisam ser observadas: "Em sua maioria, as empresas brasileiras são de médio e pequeno porte, são constituídas como sociedades limitadas (empresas de capital fechado) e não têm acesso às bolsas de valores" (BUAINAIN, et al., 2017, p.103). O tipo societário mais utilizado no Brasil é das sociedades limitadas, e não das sociedades anônimas, principalmente devido ao alto custo de manutenção de uma S.A. no país (EID JUNIOR, 2012); e, neste universo das sociedades limitadas, mais de $70 \%$ possuem capital social na faixa de $\mathrm{R} \$ 50$ mil ou menos (MATTOS FILHO, Et al. 2014). Isso significa que as reformas jurídico-institucionais promovidas nos anos 1990 não foram capazes de alcançar a realidade da grande maioria das empresas brasileiras, 
que não se enquadram nos requisitos de capital e garantias exigidas para acessar as fontes de financiamento formais e tradicionais.

A alternativa buscada por essas empresas, considerada mais informal, que despontou do próprio mercado e que vem ganhando espaço rapidamente no Brasil, é a do investimento-anjo. Seguindo a lógica das instituições informais que são incorporadas pelo direito, a regulação vem sendo formalmente instituída com a finalidade de balizar esta forma de transação já previamente aclamada pelo mercado.

\section{INSTITUIÇÕES JURÍDICAS E ECONÔMICAS NO CONTEXTO DO INVESTIMENTO-ANJO}

Douglass North trata da eficiência adaptativa, segundo a qual uma sociedade será mais eficiente quanto maior for sua capacidade de se adaptar às mudanças que ocorrem ao longo do tempo (GALA, 2003). As mudanças são profundas e rápidas na esfera econômica, e demandam dos reguladores uma agilidade para esta eficiência adaptativa.

A evolução permeada por tentativas e erros ao longo de inúmeras gerações possibilitaram algum aprendizado sobre aspectos que funcionam e são essenciais, e sobre outros que não funcionam na economia (NORTH, 1994). Embora cada país constitua um sistema complexo de variáveis, há fatores reconhecidamente fundamentais em todo o mundo para o desenvolvimento, sendo que a existência de parâmetros de confiança no ambiente negocial e entre os agentes privados é imprescindível.

Segundo Cooter e Schafer (2013, p. 05), o crescimento econômico é mais acelerado em países que já são ricos, se comparado com os países mais pobres, dificultando o catch up destes em relação àqueles. Os investimentos em inovações são os mais determinantes para essa aceleração. Entretanto, inovar envolve assumir riscos e despender de grande quantidade de capital; portanto, para que seja possível, é preciso resolver o dilema da confiança mútua e atrair os investidores.

A confiança é uma questão jurídica, promovida a partir da redução dos problemas de agência e assimetrias informacionais. Isso significa que a dependência da trajetória pode ser vencida quando há acertos nas instituições jurídicas neste âmbito.

Compete, então, ao direito o papel de aumentar os custos à adoção de comportamentos oportunistas e predatoriamente autointeressados dos agentes econômicos, e estimular a realização de transações mutuamente benéficas para atingir um ponto de equilíbrio, quando todos os sujeitos envolvidos estão maximizando os próprios interesses simultaneamente.

O conceito-chave para o entendimento da prosperidade proposta por North é o de instituições eficientes. $\mathrm{O}$ autor define [...] um arranjo institucional deste tipo: capaz de igualar o retorno privado ao retorno social das atividades econômicas dos agentes de uma dada sociedade. Uma matriz institucional eficiente será aquela capaz de estimular um agente ou organização a investir numa atividade individual que traga retornos sociais superiores a seus custos sociais. (GALA, 2003, p.97)

Para Schapiro (2010), os instrumentos regulatórios devem estabelecer mecanismos de governança bem desenhados e efetivos, para incentivar os administradores a perseguirem os seus objetivos de modo compatível com os interesses dos investidores. Se houver sensação de vulnerabilidade institucional, os investidores tendem a desempenhar comportamentos de autopreservação, tendo a sua participação em empreendimentos desencorajada. 
Para a maioria das empresas iniciantes e sociedades limitadas, os recursos financeiros, em um primeiro momento, vêm dos fundadores, familiares e amigos (fase dos $3 \mathrm{Fs}$ ) - mas estes recursos costumam ser insuficientes para escalas maiores, impondo-se a necessidade de buscar investimentos externos; a captação de recursos em bancos públicos e privados enfrenta altas taxas de spread bancário; e os investimentos feitos por fundos de venture capital estão em patamares de US\$2.00o.ooo, que nem sempre são condizentes com a realidade ou as necessidades da empresa que está buscando o financiamento. A alternativa mais atraente passa a ser do investimento-anjo (WILSON, 2015, p. 05).

Os investidores-anjos, frequentemente, são empresários já experientes, que possuem uma fonte de capital próprio para investir em empresas que tenham potencial de crescimento, prescindindo da intermediação de um banco público ou privado. O que torna esta transação empresarial ainda mais atrativa, é o fato de não ser exclusivamente financeira, tendo em vista que o investidor-anjo poderá contribuir também apoiando o empreendedor transmitindo e compartilhando o seu know-how, experiências e rede de relacionamentos, aumentando as chances de sucesso do negócio.

Os principais riscos que podem ser evitados através de instituições jurídicas eficientes são a assimetria informacional e os problemas de agência. A assimetria informacional ocorre quando os agentes envolvidos detêm níveis de informação (quantitativa ou qualitativamente) diversos em relação ao outro que participa da mesma transação, abrindo espaço para comportamentos oportunistas diante de ações ou intenções ocultas que podem causar desvantagens nas tomadas de decisões ou negociações. O oportunismo, na definição de Williamson (1985, p.47), seria o comportamento estratégico de uma das partes para distorcer informações de modo a aumentar as suas vantagens frente a outra parte em uma transação.

No contexto dos investimentos-anjo, a confiança mútua, segundo Cooter e Schafer (2013, p.19), procede do princípio que o investidor deverá confiar que o empreendedor não irá se apropriar do capital mas não entregar os resultados esperados, enquanto o empreendedor deve confiar que o investidor não irá se apropriar da sua ideia e disseminá-la ou aplicá-la em um empreendimento próprio.

Após a realização do investimento, emergem os custos de agência, que têm como fato gerador os possíveis conflitos de interesse entre o administrador da empresa e o investidor, devendo haver um monitoramento mútuo a fim de verificar e fazer cumprir, da maneira mais eficiente, os objetivos pretendidos por cada um na transação. Na delegação de tarefas, é comum que haja divergência de interesses (FONSECA e DOMINGUES, 2018, p.329).

Assimetria informacional e problemas de agência são inevitáveis, pois decorrem da própria natureza humana de racionalidade limitada, entretanto, direito e economia interagem na criação de soluções para mitigar riscos mantendo a atratividade desta modalidade de investimentos.

Os mecanismos de controle e governança - transparência, equidade, prestação de contas e responsabilidade corporativa (OECD, 2015) -, favorecem o cumprimento das promessas entre os agentes. Quando as promessas são cumpridas, maximizam-se os resultados econômicos. Os pilares da governança corporativa são estimulados no contexto do investimento-anjo, pois a própria realização do investimento está condicionada à elaboração e apresentação de um plano de negócios, com metas que podem ser cobradas periodicamente. Do cumprimento das metas dependerá a opção, ao final do período do investimento-anjo, pela conversão do resgate em participação societária, nos contratos de mútuo conversível. Da mesma forma, há direitos que somente são adquiridos conforme as metas sejam atingidas (vesting), e que também são eficientes para mitigar riscos de conflitos de interesse ou falhas na execução contratual. 
Enquanto o negócio é embrionário e não provou o seu potencial, o investidor não é sócio e não corre os mesmos riscos que o empreendedor - principalmente diante das mais variadas obrigações impostas pelo direito brasileiro, incluindo a carga tributária e trabalhista, que podem ensejar desconsideração da personalidade jurídica. No contexto do investimentoanjo, a estrutura societária e de capital da empresa é reajustada conforme o negócio evolui. Essas transformações gradativas ajudam a mitigar os riscos da assimetria informacional, pois as decisões podem ser tomadas conforme as informações vêem à tona. (FONSECA e DOMINGUES, 2018, p. 343-344).

Diante dos obstáculos judiciais tipicamente brasileiros enfrentados pelas empresas, especialmente a desconsideração da personalidade jurídica, que multiplica os riscos do empreendedorismo, a Lei Complementar no 155/2016, trouxe maior segurança jurídica, em seu artigo 61-A, §4ํㅜㄹ inciso II, ao determinar que o investidor-anjo não responderá por obrigações da empresa, nem mesmo em caso de recuperação judicial.

Em que pese não haver formalizado o direito de gerência ou voto ao investidor - o que apenas aumentaria seu leque de obrigações e, consequentemente, de riscos -; a participação na forma de mentoria e aconselhamento é permitida e até mesmo almejada, pois se trata de smart money (D’ASCENZO, 2009).

A participação ativa do investidor-anjo na empresa investida, na forma de mentoria, é um mecanismo de controle eficiente, que reduz tanto a assimetria informacional, quanto os custos de agência. A assimetria informacional é reduzida porque o investidor é capaz de acompanhar as rotinas da empresa e aconselhar o empreendedor nas tomadas de decisões, garantindo que o dinheiro investido será bem aproveitado.

Em um estudo promovido no estado do Rio de Janeiro, analisando as empresas que contam com investidor-anjo, constatou-se que nem sempre os investidores quiseram assumir papeis relevantes na governança corporativa, optando apenas por "investir sem dirigir". Entretanto, mesmo nestes casos, em geral, os investidores influenciaram de forma positiva a administração da empresa, com a exigência de relatórios financeiros melhor estruturados, na melhoria de alguns processos ou até mesmo causando uma mudança de postura dos próprios empreendedores. Outros investidores, orientam e influenciam de forma direta no desempenho das empresas, pondo em prática o verdadeiro conceito do smart money. Há também investidores que não participam de forma ativa na gestão das empresas, mas oferecem aos empreendedores apoio em outros campos, principalmente através de sua rede de contatos, melhorando significativamente o desempenho das empresas. (BARROS, et al, 2017, p.59)

A Lei 155/2016, prioriza o investimento em microempresas e empresas de pequeno porte, ou seja, que ainda contam com receitas brutas de valor baixo, mas que estejam exercendo atividades de inovação. Além disso, os aportes não impedem a fruição do Simples Nacional, pois não são considerados receitas da sociedade. A legislação está em consonância com o princípio da ordem econômica, garantido no artigo 170, inciso IX, da Constituição Federal, que prevê o tratamento favorecido para as empresas de pequeno porte.

Protege-se, ainda, o empreendedor do comportamento predatório ou abusivo do investidor ao prever um teto para o retorno financeiro, em um trade-off pela isenção de responsabilidades, sem prejuízo da possibilidade das partes optarem por converter o resgate do investimento em participação societária (MARINHO, 2017, p. 32 ).

E, para os investidores, a reunião em associações de investidores-anjo mitiga os riscos ao proporcionar uma rede de apoio, compartilhamento de experiências e a possibilidade de diluir o valor investido entre um grupo de investidores. Ou seja, há a possibilidade de investimentos maiores para as empresas, com menores riscos para todos os envolvidos. 
A interseção de instituições jurídicas e econômicas, então, reduz os custos de transação entre indivíduos com interesses convergentes, delimitando as responsabilidades ex post de cada um e fornecendo os mecanismos que tornam esta relação comercial mais segura. A intervenção estatal precisa respeitar limites para não engessar as relações econômicas, que precisam de espaço e flexibilidade para evoluir e atender às novas demandas que surgem a todo momento. No contexto do investimento-anjo, a regulação é relativamente recente e não há dados empíricos suficientemente consistentes para analisar os reflexos no médio e longo prazo. A breve análise teórica formulada no presente artigo, entretanto, indica que a regulação teve como foco mitigar os principais pontos que ensejam riscos e custos, mas ainda mantendo uma necessária flexibilidade negocial.

\section{DESENVOLVIMENTO ECONÔMICO ATRAVÉS DE INVESTIMENTO-ANJO}

No mais recente relatório apresentado pela Global Entrepreneurship Monitor, verifica-se que, no Brasil, houve aumento do empreendedorismo por necessidade, devido às altas taxas de desemprego e a busca por fontes de renda alternativas por pessoas com pouca ou nenhuma experiência em empreender. Além disso, constatou-se que ainda há pouco apoio do governo, muitos impostos e burocracia, que dificultam o crescimento de um negócio, principalmente nos primeiros anos de sua criação (BOSMA e KELLEY, 2019, p.43). Não surpreende, então, que em torno de $42 \%$ das empresas não sobrevivam por mais do que 2 anos de funcionamento (SEBRAE, 2016). Para contornar esses entraves, o investimento-anjo e a combinação smart money é essencial.

Os mercados de capitais (tradicional e venture) não são suficientes para financiar o desenvolvimento do país, pois não envolvem as pequenas empresas eas empresas iniciantes, que, muitas vezes, têm como objetivo gerar inovações. Este cenário ainda configura impedimentos na alavancagem de inovações, e mantém o país mais dependente do financiamento público e importação de tecnologia (BUAINAIN, et al., 2017, p. 104).

Segundo Schumpeter (1988), a falta de financiamento afeta principalmente os novos empreendedores, então, nos países onde não há apoio financeiro para negócios de menor porte, a inovação tende a ser abortada ainda na fase do projeto. Nestes países, apenas as grandes emrpesas, que podem usufruir de recursos próprios, é que são capazes de investir em inovações que vêm a ser bem-sucedidas. Essas características culminam em redução da concorrência e até mesmo situações de abuso do poder econômico, prejudicando o bem-estar de toda a população consumidora. Sendo que, para Cooter e Schafer (2013, p. 20), o crescimento econômico sempre "ocorre através de empreendimentos inovadores", ainda que a forma de inovação varie de tempos em tempos. E, para Rister (2007), um dos mais importantes princípios do desenvolvimento é o da difusão de conhecimento econômico, evitando a concentração de poder de pequenos grupos.

Isso significa, então, que o investimento-anjo em tudo está conectado aos meios e fins do desenvolvimento econômico, não apenas ao possibilitar aumento de renda, inovações e empregos nas empresas investidas, mas também ao realizar a difusão de know-how, que aumenta as capacidades produtivas e intelectuais dos novos empreendedores.

No Brasil, o investimento-anjo é, ainda, um meio de se desviar da trajetória de dependência do setor público para inovações e financiamentos, fortalecendo a parceria entre agentes privados.

O reconhecimento da crescente importância do investimento-anjo em todo o mundo tem motivado políticas públicas e medidas como incentivos fiscais, campanhas de informação 
e educação, entre outras. Programas específicos, como incubadoras, aceleradoras e associações de angels, tornaram-se cada vez mais populares. Iniciativas para criar uma cultura mais empreendedora também são vitais, pois, em muitos países, o medo e o custo do fracasso ainda são maiores do que as oportunidades e habilidades percebidas para empreender (WILSON, 2015, p. 04)

No Brasil, (BOSMA e KELLEY, 2019, p.67), as oportunidades percebidas estão em 31.4 pontos, em uma escala de o a 100; as capacidades percebidas, em 54.3; o medo de falhar foi manifestado em uma escala de 32.6; mas as intenções empreendedoras ainda são baixas: avaliadas em 26.1 pontos. Portanto, ainda que o investimento-anjo seja uma transação entre agentes privados, a atuação do setor público é determinante para o seu pleno desenvolvimento, criando políticas públicas eficientes para reduzir custos e incentivar as boas práticas entre os agentes econômicos.

\section{CONCLUSÃO}

Criar inovações é, de forma geral, uma atividade que demanda muito capital e envolve altos níveis de risco. Grandes empresas, já consolidadas no seu mercado de atuação, podem investir em inovações com recursos humanos e financeiros próprios, mas esse oligopólio da inovação acaba gerando maior concentração de poder e pode causar prejuízos para a concorrência e a população consumidora.

Os novos empreendedores, startups e empresas de pequeno porte, podem esbarrar em obstáculos para acessar os financiamentos bancários ou estatais e, menos ainda, detêm capital próprio para a implementação de seus projetos inovadores. Os investidores-anjo, então, preenchem esta lacuna na economia brasileira, rompendo a trajetória de dependência dos bancos públicos. Além disso, oferecem vantagens que vão além dos aspectos econômicos: desenvolvem um compartilhamento de capacidades intelectuais, redes de contatos e expertise de mercado, que são igualmente determinantes para o sucesso da empresa investida.

Dessa forma, o empreendedorismo no Brasil, que tem se propagado também por necessidade diante das altas taxas de desemprego, encontra amparo e favorecimento no investimento-anjo.

Cabe ao Estado, então, através do direito, promover as instituições que viabilizam esse tipo de investimento com maior segurança jurídica, reduzindo custos de transação e garantindo maior confiança entre as partes. A Lei Complementar no 155/2016 reafirma o princípio de tratamento favorecido para empresas de pequeno porte no Brasil, proporciona um ambiente de estímulo à inovação, e protege empreendedores e investidores ao delimitar riscos e responsabilidades - dentre as quais a isenção de responsabilidade do investidor por atos sociais é a mais relevante, dada a excessiva burocracia brasileira e os recorrentes casos de desconsideração da personalidade jurídica. Encontra-se, ainda, um ponto de equilíbrio entre o poder de administração do empreendedor e o poder de fiscalização do investidor. É mantida a liberdade contratual sobre os lucros, o resgate do investimento ou a sua conversão em participação societária.

Dessa forma, a regulação representa um avanço para o investimento-anjo no Brasil, mas deve ser combinada com políticas públicas relacionadas às incubadoras, aceleradoras e estímulos para associações de investidores, além de fomentar a cultura empreendedora, garantindo que as oportunidades percebidas sejam maiores do que medo e custo do fracasso.

Criadas as condições favoráveis para que o investimento-anjo atinja o seu potencial máximo, este converte-se em um efetivo instrumento de desenvolvimento econômico. 


\section{REFERÊNCIAS}

ALCOFORADO, Fernando. Globalização e desenvolvimento. São Paulo: Nobel, 2006.

ALMEIDA, Paulo Roberto de. O Brasil e o sistema Bretton-Woods: instituições e políticas em perspectiva histórica. In: SILVA, Roberto Luiz; MAZZUOLI, Valerio de Oliveira. (Orgs.) O Brasil e os acordos econômicos internacionais. São Paulo: Revista dos Tribunais, 2003, p.30-64.

BARROS, Giovanni E; TODA, Favio A.; RAMOS FILHO, América da C. O papel dos investidoresanjos em empresas investidas: um estudo exploratório com empresas do estado do Rio de Janeiro. Cadernos de Gestão e Empreendedorismo. V.5, ํㅜ․ Setembro-Dezembro de 2017, p.47-61.

BERNARDI, Bruno Boti. O conceito de dependência da trajetória (path dependence): definições e controvérsias teóricas. Revista Perspectivas, São Paulo, v. 41, p. 137-167, jan./jun. 2012.

BOSMA, Niels; KELLEY, Donna. Global Entrepreneurship Monitor - 2018/2019 Global Report. Global Entrepreneurship Research Association (GERA), 2019.

BRESSER-PEREIRA, Luiz Carlos. Crescimento e desenvolvimento econômico. Notas para uso em curso de desenvolvimento econômico na Escola de Economia de São Paulo da Fundação Getúlio Vargas, 2007.

BUAINAIN, Antonio M.; LIMA JUNIOR, Irineu de S.; CORDER, Solange. Desafios do financiamento à inovação no Brasil. In: COUTINHO, Diogo R.; FOSS, Maria Carolina; MOUALLEM, Pedro Salomon. (Orgs.) Inovação no Brasil: avanços e desafios jurídicos e institucionais. $1^{\mathrm{a}}$ Ed. Blucher: Open Access. p. 97-123, 2017.

BUTLER, Eamonn. Classical liberalism. The Institute of Economic Affairs. Great Britain, 2015 .

D'ASCENZO, C. A case study on preinvestment behavior and deal flow in an angel investment group. 198 f. Dissertação (Administração) - University of Phoenix, Arizona, 2009.

COASE, Ronald H. The Problem of Social Cost. The Jounal of Law and Economics. Out de 1960, Vol. 3, pp. o1-44.

COASE, Ronald H. The task of the society. Institutional Society for New Institutional Economics. 1999, Vol. 02, 02, pp. 01-08.

COOTER, Robert D.; SCHAFER, Hans-Bernd. Solomon's Knot: How Law Can End the Poverty of Nations. Princeton University Press, 2013.

EID JUNIOR, William. Custos de manter uma Sociedade Anônima no Brasil. GV - Centro de Estudos em Finanças - EAESP. Dezembro de 2012. 
FIANI, Ronaldo. Tendências da Regulação Econômica no Caso Brasileiro: uma reflexão a partir do debate internacional. Revista de Economia Contemporânea, Rio de Janeiro, v. 5, n.ed. esp, p. 155-177, 2001.

FONSECA, Victor C. DOMINGUES, Juliana O. Financiamento de startups: aspectos econômicos dos investimentos de alto risco e mecanismos jurídicos de controle. Revista de Direito Econômico e Socioambiental, Curitiba, v. 9, n. 1, p. 319-354, jan./abr. 2018.

GALA, Paulo. A teoria institucional de Douglass North. Revista de Economia Política, vol. 23, no 2 (90), abril-junho/2003, p.89-105.

GONÇALVES, Oksandro; RIBEIRO, Marcelo M. Tributação e desenvolvimento regional: uma análise econômica dos benefícios fiscais concedidos para empresas instaladas na Zona Franca de Manaus e a guerra fiscal entre estados. Revista Pensar, Fortaleza, v. 20, n. 2, p. 451-504, maio/ago. 2015 .

MARINHO, Leonardo E. M. Campos. Startups: A mitigação dos riscos nos investimentos em startups de base tecnológica. Monografia. 63f. LLM em Direito Societário. INSPER, São Paulo, 2017.

MATTOS FILHO, Ary O; Et al. Radiografia das Sociedades Limitadas. Núcleo de Estudos em Mercados e Investimentos. FGV Direito SP, agosto de 2014.

MOREIRA, Vital. A ordem jurídica do capitalismo. 3. ed., Coimbra: Centelho, 1978.

NASSER, Salem Hikmat. Fontes e normas do direito internacional: um estudo sobre a soft law. São Paulo: Atlas, 2005.

NORTH, Douglass C. Economic performance through time. The American Economic Review. June 1994, 84, pp. 359-368.

NORTH, Douglass C. Intitutions, institutional change and economic performance, Cambridge: Cambridge University Press, 1990.

OECD, G2o/OECD. Principles of Corporate Governance. OECD Publishing, Paris, 2015. Disponível em: https://www.oecd.org/corporate/principles-corporate-governance.htm Acesso em: 13 de junho de 2019.

REIS, José. Estado e mercado: Uma perspetiva institucionalista e relacional. Revista Crítica de Ciências Sociais [Online], noo 95, p.11-34, dezembro de 2011.

RIBEIRO, Marcia Carla Pereira; GALESKI JUNIOR, Irineu. Teoria geral dos contratos: contratos empresariais e análise econômica. s.l. : Elsevier, 2009.

RISTER, Carla A. Direito ao desenvolvimento: antecedentes, significados e consequências. Rio de Janeiro: Renovar, 2007. 
SCHUMPETER, Joseph. A Teoria do desenvolvimento econômico. São Paulo: Nova Cultural, 1988.

SEBRAE - Serviço Brasileiro de Apoio às Micro e Pequenas Empresas. Sobrevivência das empresas no Brasil. Relatório Final, outubro de 2016. Disponível em: https://datasebrae.com. br/wp-content/uploads/2017/o4/Sobreviv\%C3\%AAncia-de-Empresas-no-Brasil-2016-FINAL. pdf Acesso em 13 de junho de 2019.

SJOSTRAND, Sven-Erik. Towards a Theory of Institutional Change, In: GROENEWEGEN, J.; PITELIS, C. e SJÖSTRAND, S. E., On Economics Institutions: Theory and Applications. Aldershot: Edward Elgar, 1995.

TREBICOOK, Michael J.; DAVIS, Kevin E. A relação entre direito e desenvolvimento: otimistas versus céticos. Revista Direito GV, São Paulo, 5(1), p.217-268, janeiro a junho de 2009.

WILLIAMSON, Oliver. The Economic Institutions of Capitalism. New York: The Free Press, 1985.

WILSON, Karen E. Policy Lessons from Financing Innovative Firms, OECD Science, Technology and Industry Policy Papers, No. 24, OECD Publishing, Paris, 2015. 